\title{
THE MAGNETIC FABRIC OF SURFICIAL DEEP-SEA SEDIMENTS IN THE HEBBLE AREA (NOVA SCOTIAN CONTINENTAL RISE)
}

\author{
ROGER D. FLOOD, DENNIS V. KENT, ALEXANDER N. SHOR and FRANK R. HALL
}

Lamont-Doherty Geological Observatory of Columbia University, Palisades, NY 10964 (U.S.A.)

(Accepted for publication June 15, 1984)

\section{ABSTRACT}

Flood, R.D., Kent, D.V., Shor, A.N. and Hall, F.R., 1985. The magnetic fabric of surficial deep-sea sediments in the HEBBLE area (Nova Scotian continental rise). In: A.R.M. Nowell and C.D. Hollister (Editors), Deep Ocean Sediment Transport - Preliminary Results of the High Energy Benthic Boundary Layer Experiment. Mar. Geol., 66: 149-167.

The anisotropy of magnetic susceptibility (AMS) of surficial sediments in the HEBBLE area (depth $4820 \mathrm{~m}$, Nova Scotian continental rise) has been measured to study the fabric of these sediments and to relate the sediment fabric to depositional conditions. Previous investigators have established that strong but variable bottom currents are important agents in redistributing bottom sediments in the area. We observe that the upper $1.5 \mathrm{~cm}$ of the sediments has a primary fabric (dominantly foliar with horizontal bedding) created by bottom-current activity while sediments deeper than $2.5 \mathrm{~cm}$ have a predominantly secondary fabric due to bioturbation. The magnitude of the AMS signal in these sediments is generally low making it difficult to measure some of the fabric elements, especially the direction of the lineated fabric. In the upper $1.5 \mathrm{~cm}$ magnetic grains are predominantly oriented parallel to the regional bathymetric contours, but there is also a significant grouping of alignments perpendicular to the contours. Primary fabrics are observed in a few of the samples from the bioturbated sediments with the magnetic grains oriented parallel to the contours. Some of the variability observed between box cores in the magnetic fabric may reflect the variability of depositional conditions within the region. An analysis of the magnitude of the AMS fabric suggests that the parameter $F_{s}$, often used to denote bottom-current fabrics, is strongly dependent on the total anisotropy and only weakly dependent on the lineated nature of the fabric. Both primary and secondary fabrics can have relatively large $F_{\mathrm{s}}$ values. Thus $F_{\mathrm{s}}$ does not appear sufficient for delineating bottom current activity in the deep sea.

\section{INTRODUCTION}

In order to interpret past depositional processes using the sedimentary record, the relationship between sedimentary processes and sediment textures in the geological record must be understood. As part of a wider study of deep-sea sedimentary fabric, we measured the anisotropy of magnetic susceptibility (AMS) of surficial sediments from the HEBBLE (High Energy Benthic Boundary Layer Experiment) area on the Nova Scotian continental rise. The alignment of magnetic grains, which gives rise to AMS is thought 
to be representative of the alignment of other grains in the sample (Hamilton and Rees, 1970), and the fabric of these grains has been used to infer the direction of paleocurrents and the nature of sedimentation conditions in various regions of the world ocean (Rees et al., 1968; Ellwood and Ledbetter, 1977, 1979; Ellwood et al., 1979; Ellwood, 1979, 1980a, b; Ledbetter and Ellwood, 1980; Auffret et al., 1981; Rees et al., 1982; Bullfinch et al., 1982; Shor et al., 1984). We measured magnetic fabric of sediments from the HEBBLE area, a well-surveyed, well-studied, and heavily instrumented region of the Nova Scotian rise, to attempt to relate the fabric of the surficial sediments to modern depositional conditions.

Several investigators have demonstrated that bottom currents are active agents of modern sediment transport at depths of $4700-5100 \mathrm{~m}$ on the Nova Scotian continental rise. Near-bottom currents with speeds up to $70 \mathrm{~cm} \mathrm{~s}^{-1}$ have been measured (Richardson et al., 1981), although current speeds average $4.6-14.1 \mathrm{~cm} \mathrm{~s}^{-1}$ over longer time periods (Weatherly and Kelley, 1982). These currents flow on average parallel to the contours, although instantaneous flow directions can be variable (Richardson et al., 1981; Weatherly and Kelley, 1982). This deep current is believed to be the equatorward return flow of poleward flow on the Sohm Abyssal Plain east of the HEBBLE area (Weatherly and Kelley, 1982); it is modified by Gulf Stream Eddies passing nearby (Kelley et al., 1982). High suspendedsediment concentrations have also been measured here suggesting active sediment transport (Biscaye et al., 1980; Spinrad and Zaneveld, 1982; Pak, 1983). Bottom photographs from across the rise have been used to infer the distribution of bottom current activity from the distribution of bed forms (Tucholke, 1982; Tucholke et al., this volume). The largest bed forms studied are aligned parallel to the regional contours (longitudinal triangular ripples), but the smallest bed forms (crag-and-tail) have variable orientations. Biological activity (especially bioturbation) is also important in these, as in most, Holocene sediments (Yingst and Aller, 1982).

\section{METHODS}

A total of 123 samples were analyzed for magnetic fabric. These samples were taken from four box cores collected on "Knorr" Cruise 101 with a Hessler-type box corer $(50 \times 50 \mathrm{~cm}$ surface area) fitted with dividers to give $10 \times 10 \mathrm{~cm}$ sub-cores (Hessler and Jumars, 1974). Doors on the corer close above the core surface to preserve the surficial sediments, and the undisturbed nature of the surface can be verified by observing bed forms, animal burrows, etc., on the sediment surface. Fabrics of the surficial sediment layers could be measured on samples from these box cores. Previous workers have noted that the magnetic properties of surficial sediments are often destroyed by standard piston coring techniques (Kent and Lowrie, 1975; Shor et al., 1984).

Samples for magnetic fabric analysis were collected by pressing sample boxes $\left(6.6 \mathrm{~cm}^{3}\right.$ boxes oriented with respect to the box core) directly into 
the sediment surface. A piston, consisting of a cubic rubber stopper, was then used to push up the entire $10 \times 10 \mathrm{~cm}$ sub-core, and the sample box was removed with a non-magnetic knife. The process was repeated to make a continuous profile of the upper $12-20 \mathrm{~cm}$ of the sediment column. A total of four box cores were studied, with two to four vertical profiles in each box core. Vertical sections of the cores were taken and X-rayed to observe the sedimentary structures, and visual descriptions of the sediments were made.

The magnetic properties of the sediment were measured following techniques described in Shor et al. (1984). These techniques and briefly described here since an understanding of the techniques and their limitations is essential to interpreting the magnetic fabric results. The susceptibility is estimated in the form of a second-rank symmetric tensor $\mathbf{k}$ which relates the magnetization $J_{i}$ induced in a sample by a field $H_{j}$ :

$J_{\mathrm{i}}=\mathbf{k}_{\mathrm{ij}} H_{\mathrm{j}}$

The susceptibility may be specified completely by six quantities, three relating to the magnitude of the principal axes $\left(k_{\max }, k_{\text {int }}\right.$ and $\left.k_{\min }\right)$ and three relating to their directions, which are orthogonal. We use a low field torsion magnetometer (similar to that described by King and Rees, 1962) employing an alternating field of up to $65 \mathrm{Oe}(\mathrm{rms})$ magnitude. The calculated sensitivity of this torsion magnetometer is $3 \times 10^{-8} \mathrm{emu} \mathrm{cm}^{-3}$ for a $1 \mathrm{~mm}$ deflection. Susceptibility differences are measured with this technique and a separate measurement of bulk susceptibility is made on an AC bridge, a less sensitive instrument, to determine the magnitude of the principle susceptibility axes. In this study we only measured the bulk susceptibility of a few samples because of equipment problems; however, the AMS results are not affected by the lack of reliable bulk susceptibility values. Although the sensitivity of this instrument as presently configured is less than that reported by other investigators (e.g., King and Rees, 1962; Ellwood and Ledbetter, 1977), it is adequate to resolve the primary fabric elements of these samples and allow us to discuss the significance of these measurements.

A check on the reliability of the measured AMS data is obtained by a redundant measurement scheme. The best-fit to the data is found by a least square method, and the differences between the calculated best-fit susceptibility values and the original readings are determined. The RMS error (\%) indicates how well the calculated values agree with the measured values. If the susceptibility distribution is well represented by a second-order symmetric tensor (a triaxial ellipsoid) then the RMS error will be low. Large errors may result from several causes. If the differences in magnetic susceptibility are small, then the low-field torsion magnetometer may not adequately resolve the shape of the susceptibility ellipsoid because the values will be near the resolution of the magnetometer. Specimens with high RMS errors and large susceptibility differences may also have susceptibility distributions which are more complex than a triaxial ellipsoid. For example, they may have several maxima in susceptibility. 
The results of AMS measurements are described in terms of the magnetic foliation plane, which is normal to the axis of minimum susceptibility, and the magnetic lineation, which lies in the foliation plane along the direction of the axis of maximum anisotropy. The dip of the magnetic foliation plane is referred to as $f$ (Crimes and Oldershaw, 1967), and an indication of the nature of alignment is obtained from the parameter $q$ (Hamilton and Rees, 1970):

$$
q=\frac{k_{\max }-k_{\text {int }}}{\left(k_{\text {max }}+k_{\text {int }}\right) / 2-k_{\text {min }}}
$$

The parameter $q$ is a measure of the relative importance of the two fabric elements of a triaxial ellipsoid: foliation and lineation. Values of $q$ vary from 0 (pure foliation) to 2 (pure lineation) with the change from dominantly foliar to dominantly linear fabric at a value of 0.67 .

The results of measurements on laboratory-deposited and natural sediments have established the characteristics of a primary magnetic fabric induced by flowing water (Granar, 1958; Rees, 1965; Hamilton and Rees, 1970). The principal feature is a well-defined magnetic foliation in or near the bedding plane. Values of $f$ are small, usually less than $15^{\circ}$ in undisturbed sediments (Hamilton and Rees, 1970; Rees and Frederick, 1974). Lineation is usually subordinate to foliation; values of $q$ typically range from 0.06 to 0.60 . These characteristics reflect the expected dominant role of gravitation acting on grains during sedimentation (producing the foliation) compared to aligning forces such as currents acting tangential to the bed (giving rise to the lineation). Secondary fabrics have been recognized which result from post-depositional alteration of primary fabric. Deformed fabrics in deep-sea sediments often result from the activity of burrowing organisms in the sediment (Rees et al., 1968; Rees et al., 1982) or due to coring disturbance (Rees and Frederick, 1974; Kent and Lowrie, 1975). Auffret et al. (1981) and Ellwood (1979) noted the possibility of other kinds of primary fabric from deposition by flowing currents. Auffret et al. (1981) permitted larger $f$ values (to $40^{\circ}$ ) to allow for the imbrication of magnetic grains. Ellwood (1979) suggested that grains which are oriented perpendicular to bottom current flow can have unrestricted $f$ values due to the rolling of grains about their long axis.

The orientations of the principal susceptibility axes and the parameters $f$ and $q$ can all be calculated from susceptibility differences measured on the torsion magnetometer. Although $f, q$ and $k_{\max }$ are not directly dependent on the value of the bulk susceptibility, the susceptibility of the sample can affect the quality of the AMS results. In general, low bulk susceptibilities will result in low susceptibility differences and the solution found for the magnetic fabric will obviously be less reliable than if the susceptibility differences are high. For all foliar samples $(q<0.67)$ the susceptibility difference which determines the lineation $\left(k_{\max }-k_{\text {int }}\right)$ will be the smallest of the three susceptibility differences calculated. For weak susceptibilities this value can approach the detectability limit of the machine resulting in errors in 
the lineation direction. If the overall anisotropy is appreciable and readily measured but there is almost no lineated portion of the fabric ( $q$ less than about 0.05$), k_{\max }-k_{\text {int }}$ will still be quite small, and the lineation direction may have a large error associated with it. All of these factors combine to make the lineation direction $\left(k_{\max }\right.$ orientation) one of the most poorly determined values of the magnetic fabric especially in foliated sediments. However, for foliated samples the foliation plane is generally well defined, and $f$ and $q$ will be well determined in most samples.

The box cores were oriented in the horizontal plane by reference to magnetic remanent directions. The remanent magnetization of each sample was determined after partial alternating field demagnetization to $20 \mathrm{nT}$ (to remove unstable or spurious components). We believe that the mean declination for each core provides an estimate of geographic north in these normal polarity, Holocene sediments. Support for this assumption comes from the agreement of the remanent inclinations with expected dipole values for the box-core site latitudes (Table 1). Azimuths of the susceptibility axes for each sample were oriented relative to mean declinations to calculate geographic coordinates. The resulting $k_{\max }$ azimuths are not simple vector quantities, but rather are bi-directional. Although alignment directions are standardized here to refer to the downward dip of the $k_{\max }$ axis, all reported $k_{\max }$ directions have conjugate values, $180^{\circ}$ different since the method described herein provides only an alignment, not a direction.

\section{MORPHOLOGY AND SEDIMENTS OF THE STUDY AREA}

The box cores were collected from within a well-surveyed area at a depth of $4815 \mathrm{~m}$ on the Nova Scotian continental rise during R/V "Knorr" Cruise 101 in April, 1983 (Table 1 and Fig.1). This site has been intensely studied during the last several years as a site for the HEBBLE (High Energy Benthic Boundary Layer Experiment; Nowell and Hollister, this volume). Past surveying of the area has been undertaken with the Scripps Deep-Tow package and with numerous bottom camera stations. Navigation within the area is by bottom-mounted acoustic transponders. The box cores are from a broad rise

\section{TABLE 1}

Summary of Knorr-101 box-core data

\begin{tabular}{llllllll}
\hline Core No. & $\begin{array}{l}\text { Lat. } \\
(\mathrm{N})\end{array}$ & $\begin{array}{l}\text { Long. } \\
(\mathrm{W})\end{array}$ & $\begin{array}{l}\text { Depth } \\
(\mathrm{m})\end{array}$ & $\begin{array}{l}\text { No. } \\
\text { samples }\end{array}$ & $\begin{array}{l}\text { Mean } \\
\text { decl }^{a}\end{array}$ & $\begin{array}{l}\text { Mean } \\
\text { incl. }^{b}\end{array}$ & $\begin{array}{l}\text { Alpha } \\
95\end{array}$ \\
\hline KN101-BC3 & $40^{\circ} 26.55^{\prime}$ & $62^{\circ} 20.65^{\prime}$ & 4817 & 37 & $276.5^{\circ}$ & $59.9^{\circ}$ & 2.61 \\
KN101-BC4 & $40^{\circ} 26.48^{\prime}$ & $62^{\circ} 20.80^{\prime}$ & 4817 & 45 & $181.1^{\circ}$ & $65.4^{\circ}$ & 2.18 \\
KN101-BC5 & $40^{\circ} 26.04^{\prime}$ & $62^{\circ} 21.13^{\prime}$ & 4823 & 18 & $199.1^{\circ}$ & $54.0^{\circ}$ & 6.20 \\
KN101-BC6 & $40^{\circ} 26.09^{\prime}$ & $62^{\circ} 21.22^{\prime}$ & 4822 & 23 & $186.7^{\circ}$ & $64.4^{\circ}$ & 3.16 \\
\hline
\end{tabular}

${ }^{a}$ With respect to the face of the box core.

${ }^{b}$ The expected value of the inclination for the study area is $60^{\circ}$. 


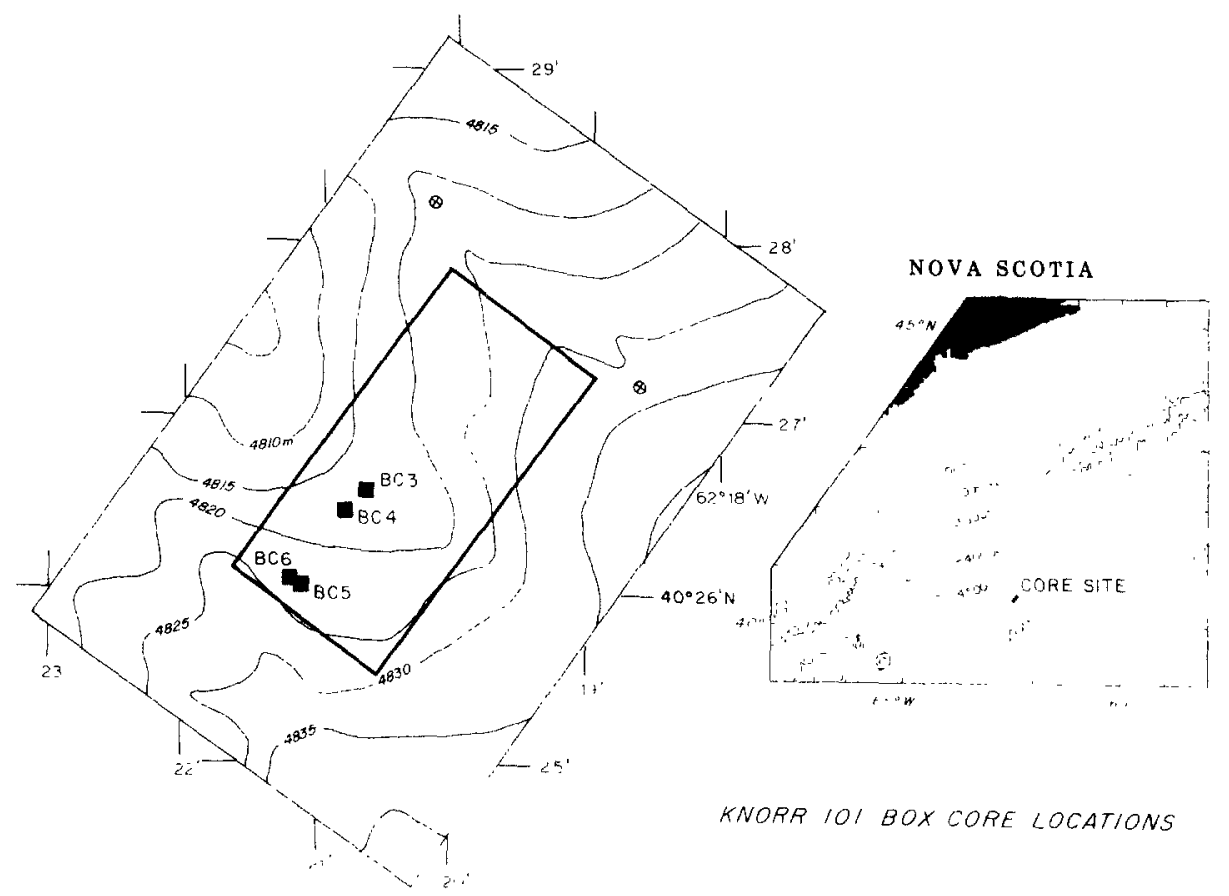

Fig.1. Location maps for the box cores used in this study. Left: locations of box cores superimposed on a bathymetric map of the HEBBLE site. Box core locations were determined with respect to bottom-mounted transponders. While the absolute locations of the cores may be in error by up to $1 \mathrm{~km}$, the relative positions of the cores and their position with respect to topography are well known. The location of the HEBBLE Box is also shown. Right: location of the detailed survey area south of Nova Scotia with respect to the regional topography.

$10 \mathrm{~km}$ wide which separates two $10 \mathrm{~m}$ deep shallow channels (Fig.1). The mean alongslope direction in this area is in the ENE-WSW direction (mean bottom-currents flow toward the WSW) and downslope is towards the SSE.

The general sediment stratigraphy is shown in Fig.2. The surface $1-2 \mathrm{~cm}$ is often a pale-brown, slick laminated clay with common foraminiferal-sand stringers. This overlies an intensely bioturbated yellowish-brown foraminiferal-rich ooze which extends to depths of greater than $20 \mathrm{~cm}$. The foraminifer Globorotalia menardii is present throughout these sediments suggesting that they are Holocene in age (Ericson et al., 1961). Occasionally, 1-2 $\mathrm{cm}$ diameter basaltic and sandstone clasts are present in the bioturbated foraminiferal ooze. X-radiographs of sediment slabs taken from the cores demonstrate that the surface sediment layer was primarily laminated in cores 3,4 and possibly 5 , although this layer is often disrupted by animal burrows. Core 6 did not have a laminated surface layer. The deeper sediment layers were generally structureless except for abundant burrows and occasional single horizons which cut across the core. Studies of short-lived radionuclides in the sediments of the HEBBLE area suggest that the upper 


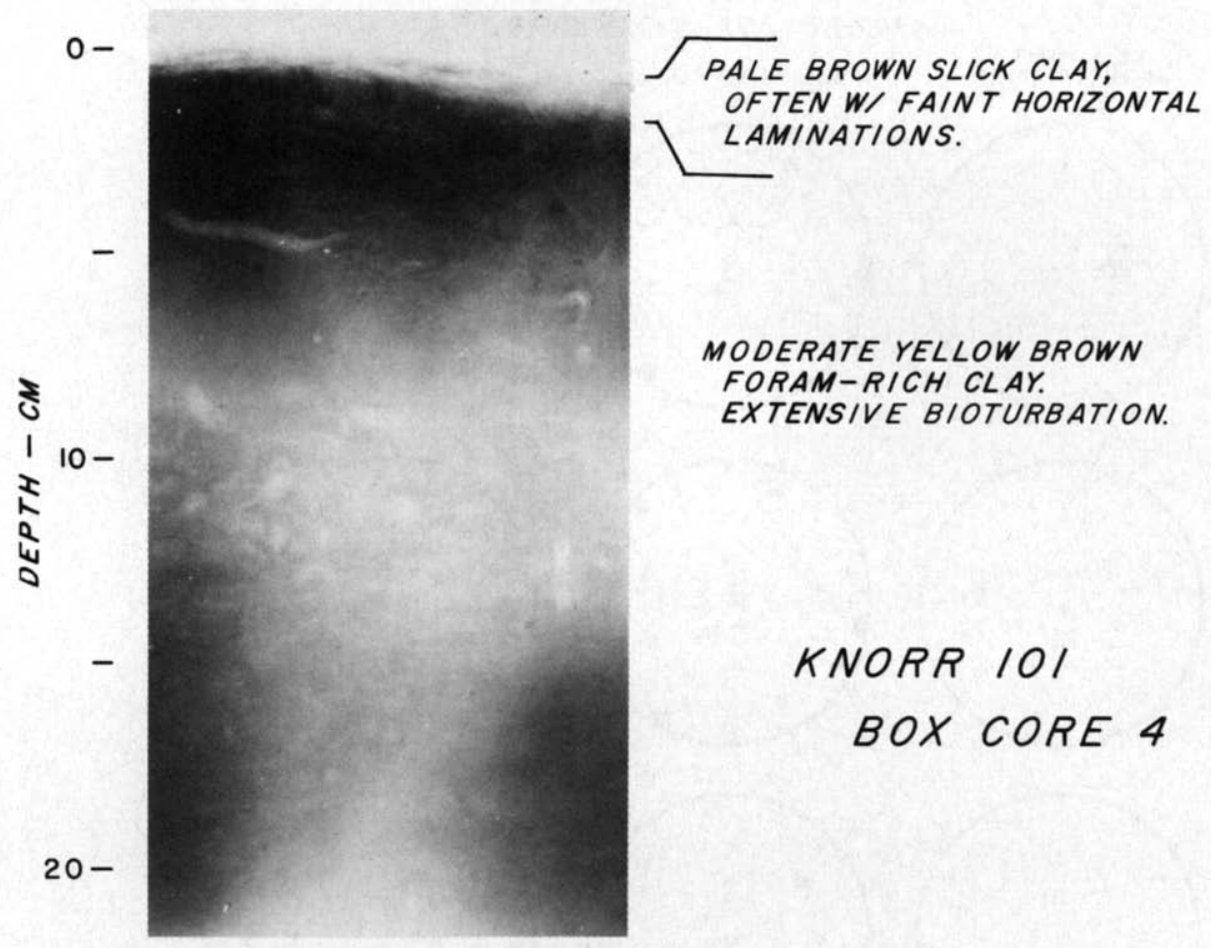

Fig. 2. A typical sediment sequence in the study area. The X-radiograph shows a weakly laminated unit overlying an intensely bioturbated unit. These units have different magnetic fabrics. Variations in exposure of the X-radiographic print result from dodging of the print to bring out the surface structure.

sediment layers are deposited rapidly, and that there is wide variability in radionuclide deposition and mixing across the HEBBLE area (DeMaster et al., this volume).

\section{MAGNETIC RESULTS}

\section{Remaǹence}

Consistent remanence data was collected from all of the box cores (Fig.3). The data are typically well grouped with alpha-95 ranging from $2.2^{\circ}$ to $6.2^{\circ}$ (Table 1). The scattering of data points around the average field position may represent secular variation in the magnetic field. The measured inclinations are approximately $60^{\circ}$. The value of the present-day magnetic field for the sampling locality is $60^{\circ}$. The consistent grouping of the magnetic remanence data suggests that the samples are not dramatically disturbed by the coring or sampling process, and that the remanence correctly records the magnetic field in these bioturbated sediments. In contrast, remanence measurements at the top of standard piston cores are routinely discarded because of disturbance during the coring process (Opdyke, 1972). 


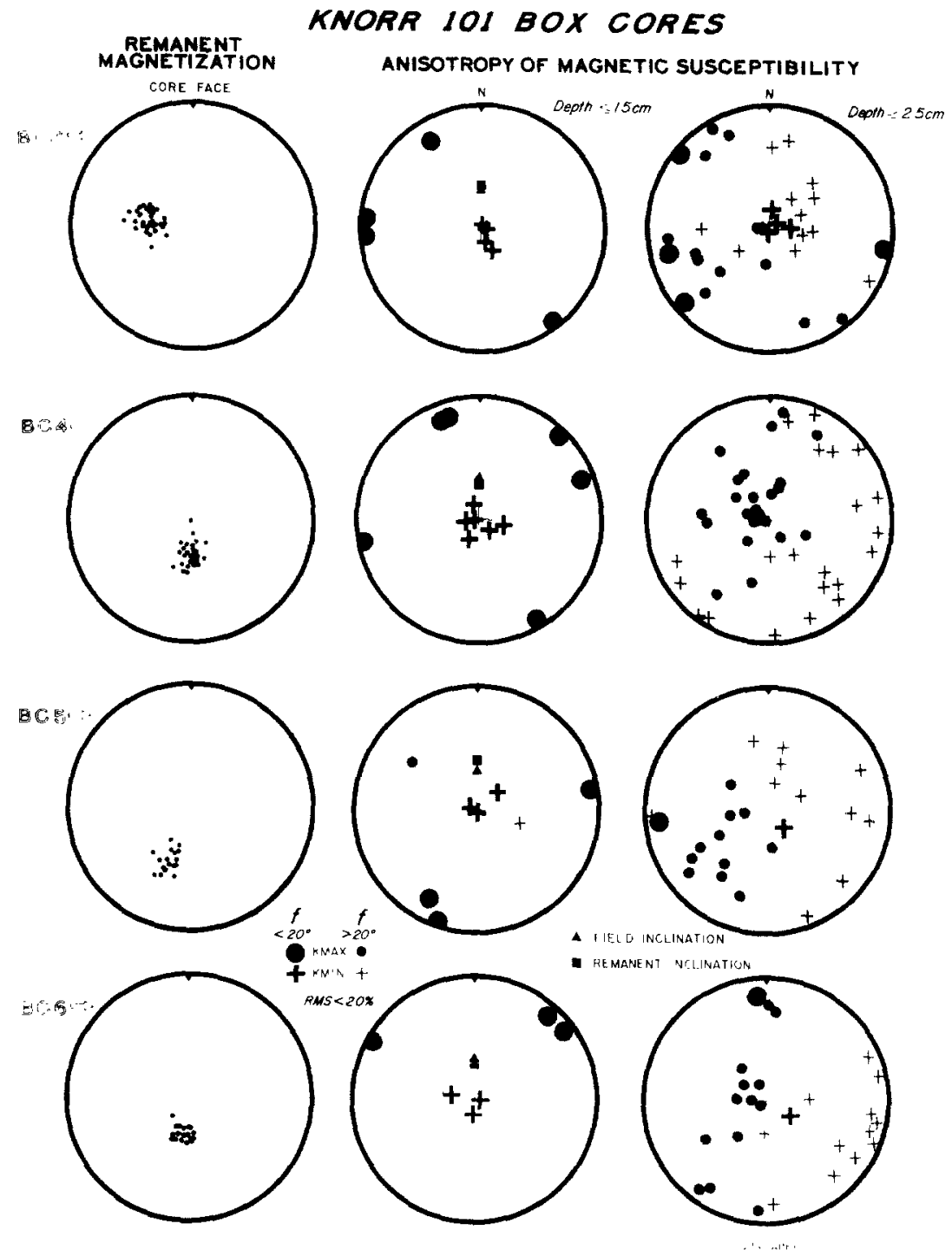

Fig. 3. Summary of magnetic data from the box cores studied. Left: remanent magnetization of all samples plotted in the reference frame of the box corer. The values are well grouped allowing us to reorient the corer to north. Center: AMS determinations $(k \max$ and $k_{\min }$, RMS $<20 \%$ ) for the upper $1.5 \mathrm{~cm}$ of the corer oriented to geographic north. The present-day field inclination and the remanent field inclination are also plotted on these projections. Larger circles and crosses indicate samples with $f<20^{\circ}$. Right: AMS determinations for samples deeper than $2.5 \mathrm{~cm}$.

\section{Anisotropy of magnetic susceptibility}

A wide variety of AMS fabrics were detected in these sediments, with the fabric of the upper, generally laminated sediment layer $(0-1.5 \mathrm{~cm})$ quite different from that of the intensely bioturbated sediments deeper than 
$2.5 \mathrm{~cm}$. The bulk susceptibility of several samples was measured subsequent to the AMS analysis, and the values are on the order of $10^{-5} \mathrm{emu} \mathrm{cm}^{-3}$, low but not atypical for deep-sea sediments. In examining the AMS fabric of these sediments the quality of the measurements and the relationship of the fabric observed to sediment processes in the area must be assessed.

\section{RMS error}

The first indication of the quality of the AMS measurement is the RMS error where small errors indicate that the fabric is well represented by a triaxial ellipsoid and large errors may be due to having only small variations in susceptibility and/or a complex sediment fabric. A histogram of the RMS error values observed in this study shows that many errors were large, generally larger than those observed by Shor et al. (1984 and unpublished data) in a study of piston cores from the Nova Scotian rise. In the present study the errors range from 2 to $80 \%$, but with a distinct grouping of errors less than 20\% (Fig.4). Shor et al. (1984) used a maximum acceptable error of $15 \%$, but because of the distribution pattern seen here we have chosen a maximum error of $20 \%$. Overall, $70 \%$ of the samples had errors less than $20 \%$ ( 86 out of 123). For the upper layer sediments alone, $85 \%$ of the samples had acceptable errors (17 out of 20 ), while for the deeper layer sediments alone only $64 \%$ had acceptable errors (66 out of 103). For large RMS errors the anisotropy parameters are not meaningful, thus in the following discussion we will concentrate on the samples with acceptable errors.

\section{KNORR 101 BOX CORES}

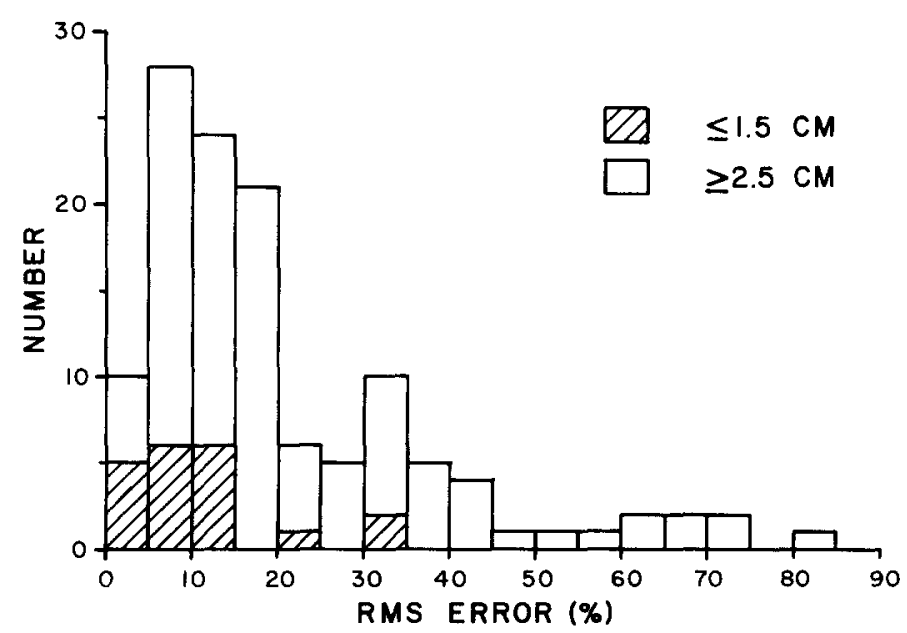

Fig.4. Histogram of RMS errors for AMS fabric determinations. The errors are generally large in these sediments in part due to the weak susceptibility anisotropies and in part due to the complex sediment fabric. For this study we have used a maximum acceptable error of $20 \%$. 
Nearly all of the large errors occur in samples where the maximum susceptibility difference is smaller than $1 \times 10^{-6} \mathrm{emu} \mathrm{cm}^{-3}$, although many samples with smaller susceptibility differences have small errors. Since we should be able to resolve the fabric of samples with susceptibility differences of this order and smaller, it is likely that these high errors result from complex fabrics. Nevertheless we note that these Holocene sediment samples have susceptibility differences smaller than those of Pleistocene samples from the same area measured by Shor et al. (1984, and unpublished data). In that study only 29 out of 315 samples had maximum susceptibility differences smaller than $1 \times 10^{-6} \mathrm{emu} \mathrm{cm}^{-3}$, and only 12 samples had errors greater than $15 \%$. Therefore we cannot entirely discount a significan contribution to the RMS error from measurement noise in the present study

$f$

Previous workers have noted that the foliation planes of natural primary fabrics are nearly parallel to the bedding plane (low $f$ values). The $f$ values of the surficial sediment layer here were generally low and thus the $k_{\max }$ vector lies near the horizontal plane (Fig.3). In contrast, $f$ values in the intensely bioturbated sediments were high indicating that the foliation is not parallel to a horizontal bedding plane. Samples from deeper in BC 3 may indicate an imbrication of about $40^{\circ}$ as there is a grouping of $k_{\min }$ orientations. Deeper in $\mathrm{BC} 4,5$, and 6 the $k_{\max }$ orientation is nearly vertical, and there is little evidence of imbrication or rolling grains (Fig.3). Shor et al. (1984) used an $f$ value of $15^{\circ}$ to distinguish between primary and secondary magnetic fabric. Values of $f$ in the surficial sediments were less than $15^{\circ}$ in 12 out of 17 samples, but no samples of the deeper, intensely bioturbated layer had $f$ values smaller than $15^{\circ}$. Therefore, we have increased the largest permissible $f$ value to $20^{\circ}$ for this study in order to search for primary fabrics in the bioturbated sediments. Sixteen out of 17 samples from the upper layer, but only six out of 66 samples from the deeper layer have $f$ values smaller than $20^{\circ}$.

$q$

Previous studies have suggested that primary sediment fabrics are dominantly foliar $(q<0.67)$ whereas disturbed fabrics can have large or variable $q$ values. In the surficial sediment layer here $q$ values were less than 0.6 in $82 \%$ of the samples with low RMS errors (14 out of 17 ), whereas low $q$ values were observed in only $41 \%$ of the samples in the bioturbated zone (27 out of 66, Fig.5). However, the six deeper samples which had low $f$ values also had low $q$ values, and all fourteen of the samples from the upper laminated layer which have $q<0.6$ also have $f<20^{\circ}$ (the one $q$ value from the surface layer greater than 1.0 has an $f$ of $18^{\circ}$ ). The independent occurrence of low $q$ values (shape parameter) in samples with low $f$ values (orientation parameter) reinforces the interpretation that these fabrics are primary. 


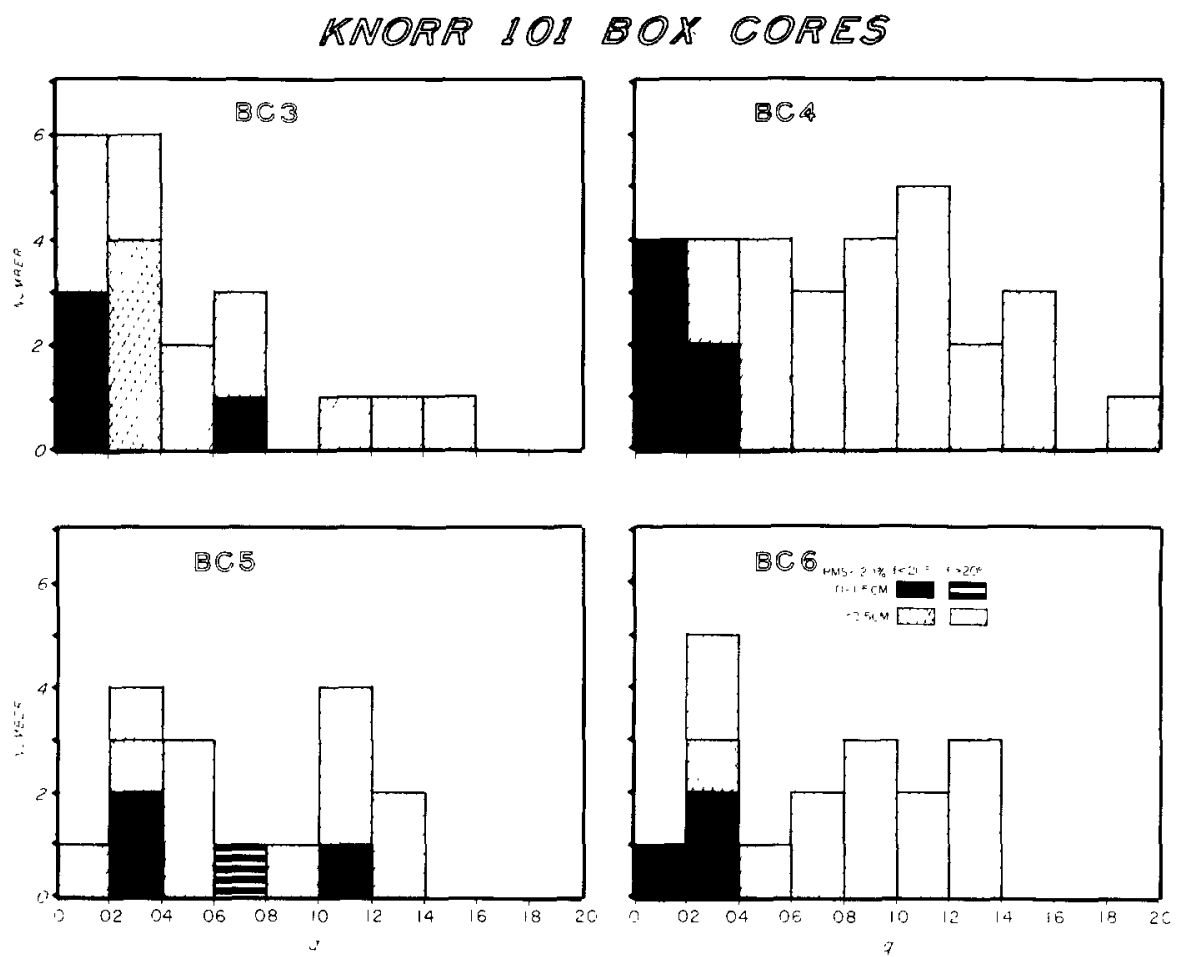

Fig. 5. Histograms of $q$ by box core. Samples from the upper $1.5 \mathrm{~cm}$ generally have $q$ values less than 0.6 indicating that the fabric is dominantly foliar. Samples from deeper than $2.5 \mathrm{~cm}$ have generally variable $q$ values indicating that the both foliar and linear elements are present. Deeper samples with $f<20^{\circ}$ have small $q$ values.

$k_{\max }$ orientation

We are primarily interested in the orientation of the maximum susceptibility for only those samples where the magnetic fabric is primary (RMS $<20 \%, f<20^{\circ}, q<0.6$; Fig.6); however, we have suggested above that the $k_{\max }$ orientation is the most difficult quantity to measure reliably, especially when $q$ is small. The 14 qualifying surficial samples show $k_{\max }$ orientations in two apparently orthogonal directions. The dominant grouping is in the east-northeast direction and its conjugate ( 7 of 14 samples are within $30^{\circ}$ of $060^{\circ}$ ) with a subordinate grouping in the south-southeast direction and its conjugate ( 4 of 14 samples are within $30^{\circ}$ of $160^{\circ}$ ). These samples all have $q$ values greater than 0.094 ; while the remaining samples all have $q$ less than 0.075 . Only six samples from the bioturbated layer qualify as potential primary fabrics ( $q$ values range from 0.20 to $0.33, f$ less than $20^{\circ}$ ). The effect of excluding samples with large $f$ values is shown in Fig.6; when all $f$ values are included there is no preferred orientation, whereas the small $f$ values alone give a weak $k_{\max }$ concentration in the east-west direction ( 3 out of 6 samples are within $20^{\circ}$ of $090^{\circ}$ ). 


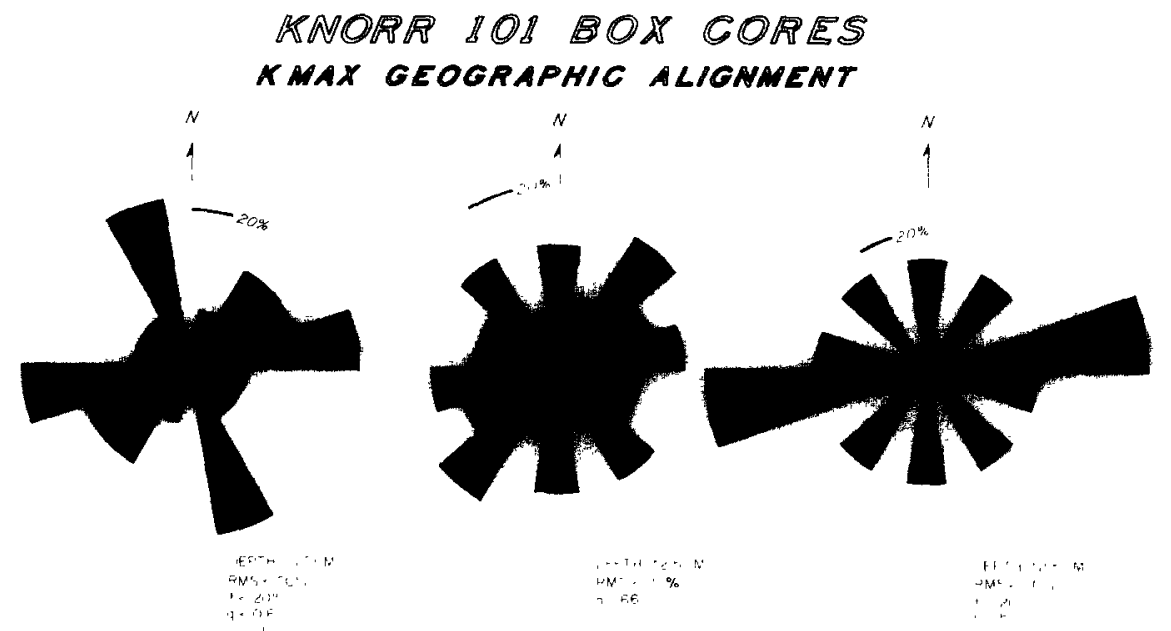

Fig. 6. Histograms of $k_{\max }$ directions in the box cores (directions grouped in $20^{\circ}$ sectors, both direction and conjugate direction shown). Left: samples from the upper $1.5 \mathrm{~cm}$ with RMS $<20 \%, f<20^{\circ}$ and $q<0.6$. Two directions are observed, parallel and perpendicular to the regional contours. Center: samples from deeper than $2.5 \mathrm{~cm}$ with RMS $<20 \%$. There is no preferred direction. Right: samples from deeper than $2.5 \mathrm{~cm}$ with RMS < $20 \%$ and $f<20^{\circ}$. These horizontally bedded, dominantly foliar samples are oriented along the contours.

\section{DISCUSSION}

These AMS measurements demonstrate that although the magnetic susceptibility fabric of the surficial sediments of the HEBBLE area is weak, we can distinguish between two distinct layers with different overall fabrics. The uppermost $1.5 \mathrm{~cm}$, which is generally a laminated unit, has a primary sediment fabric (low error, low $f$, low $q$ ). This probably results from sediment deposition directly from the water column, perhaps under the influence of bottom currents. In contrast, the sediments deeper than $2.5 \mathrm{~cm}$, a bioturbated foraminiferal-rich ooze, have a dominantly secondary fabric (weak susceptibility differences, high errors, high $f$, high and variable $q$ ) which appears to have been induced by biological reworking. However, within this bioturbated unit there are six samples which appear to have a primary fabric, perhaps reflecting levels of reduced bioturbation.

Many workers have used the orientation of $k_{\max }$ as an indication of the direction of sediment transport by bottom currents in the deep sea (Rees et al., 1968; Ellwood and Ledbetter, 1977, 1979; Ellwood, 1979, 1980a, b; Ledbetter and Ellwood, 1980; Auffret et al., 1981; Rees et al., 1982; Shor et al., 1984). In most of these studies the $k_{\max }$ orientation was thought to be parallel to the current direction, although in some instances the $k_{\max }$ alignment was perpendicular to the bottom current direction (e.g., Ellwood and Ledbetter, 1977; Ellwood, 1979). We have noted in this study that the magnetic anisotropy of these Holocene sediments is in general quite weak, 
much weaker than the anisotropy observed in Pleistocene sediments in this area (Shor et al., 1984). Because of the weak anisotropies, there may be considerable uncertainty in these $\boldsymbol{k}_{\max }$ directions although we believe that our results are representative of the fabrics present. We observe in this study that there are two preferred $k_{\max }$ directions in the surficial layers, along and across the regional contours, and one preferred direction in the bioturbated sediments, along the contours. Since there is at present little evidence that downslope processes have formed or modified the surficial sediments in the HEBBLE area, we must include the possibility that the observed primary fabrics reflect current activity observed in the HEBBLE area today. These currents flow on average along contours, but there is considerable variability in flow direction. The variability in $k_{\max }$ orientation which we observe in the surficial sediment layer may represent a statistical variation typical of these sediments (half of the samples aligned parallel to the mean current and one third aligned perpendicular to the mean current). This variation may come about if there are different possible alignments of grains deposited from a flow (parallel vs. perpendicular), or if there are variations in bottom current strength and direction over long and short time periods. Rees et al. (1982) also noted a bimodal distribution of $k_{\max }$ azimuths in surficial sediments from the Rockall Trough.

Other parameters, based on the actual magnitude of the anisotropy axes, have been used as indicators of the strength of the current alignment of abyssal sediments. Ellwood and Ledbetter (1977) used the parameter $F_{\mathrm{s}}$ as an indicator of bottom-current activity, and the parameter has since been used in a number of studies (Ellwood and Ledbetter, 1979; Ellwood et al., 1979; Ellwood, 1980a, b; Ledbetter and Ellwood, 1980; Bullfinch et al., 1982). We have not discussed the absolute magnitude of the anisotropy, in part because we did not measure the mean susceptibility of all of our samples. However, the bulk susceptibility was measured on a representative number of samples here, and on all of the samples used by Shor et al. (1984 and unpublished data) so that we can attempt an evaluation of the significance of the anisotropy magnitude and $F_{\mathrm{s}}$ with respect to our data. Ellwood and Ledbetter (1977) defined $F_{\mathrm{s}}$ as

$F_{\mathrm{s}}=\frac{k_{\max }}{\left(k_{\text {int }} \times k_{\min }\right)^{1 / 2}}$

The principal susceptibilities can be calculated with reference to a standardized or average bulk susceptibility, constant for all samples, (giving $F_{\mathrm{s}}$ ) or to the individual measured susceptibility values (giving $F_{\mathrm{s}}^{\prime}$ ). Ellwood and Ledbetter (1977) use $F_{\mathrm{s}}$ as a measure of the strength of the magnetic susceptibility because it emphasized the value of $k_{\max }$, or long-axis alignment, which they infer to be a measure of the linear fabric. Also, by using a constant bulk susceptibility, fabric changes which are caused by betweensample variability in initial susceptibility are minimized. However, $F_{\mathrm{s}}$ appears to be a more complex indicator of sediment fabric than initially apparent. We have attempted to relate $F_{s}$ to other indicators of the 


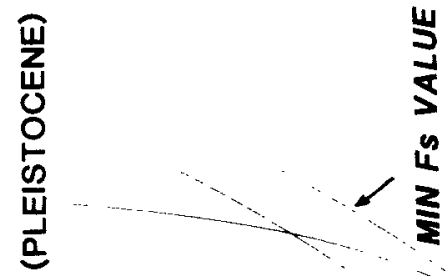

峞

zo

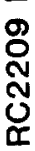
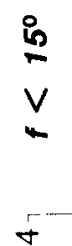

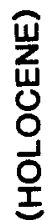

峞

홈
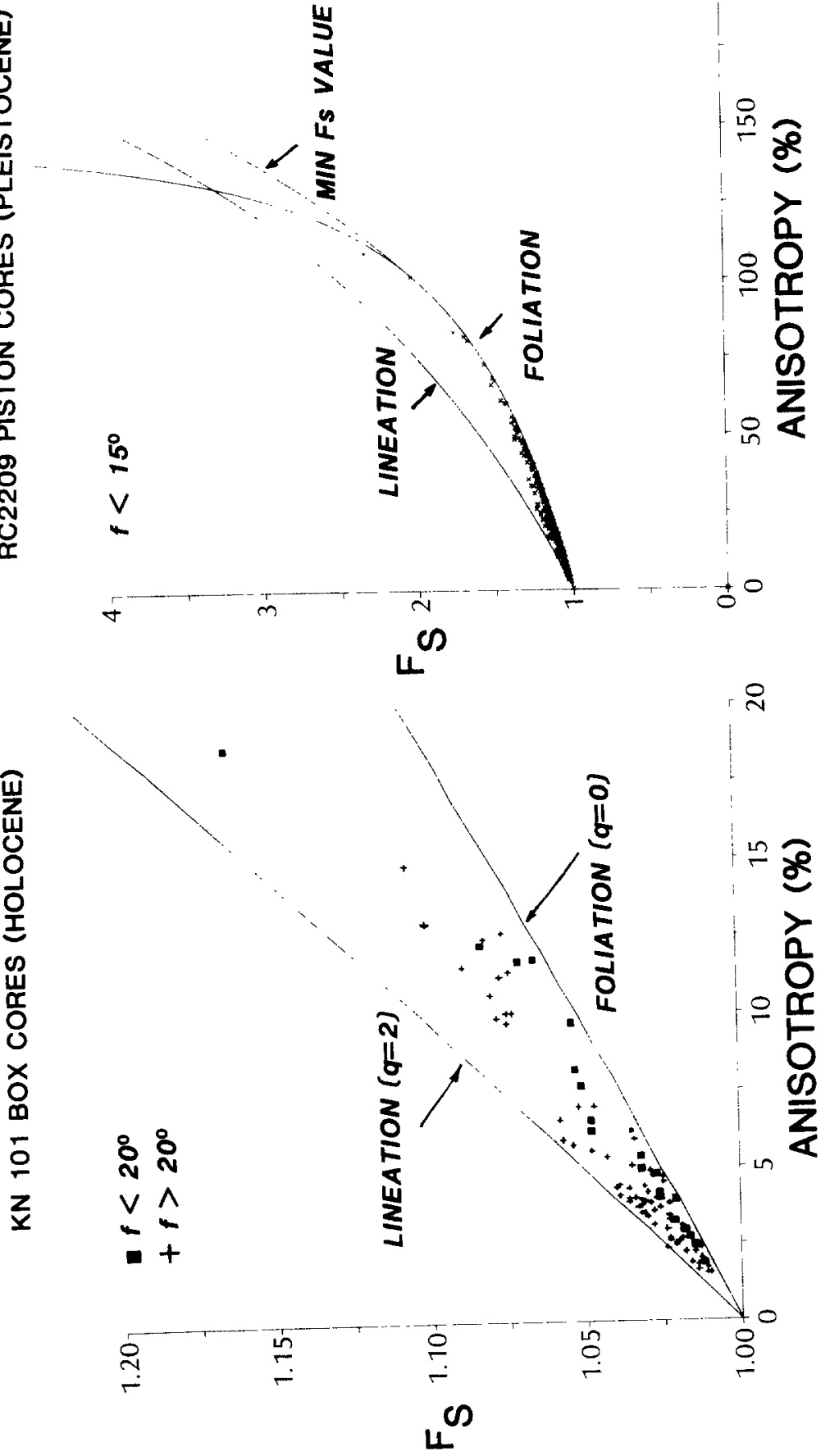

$u^{\infty}$

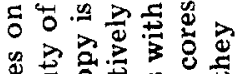

i

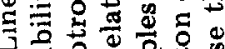

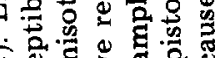

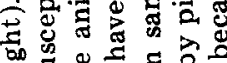

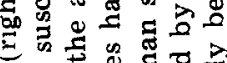
Q

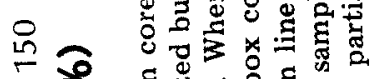
这 $\dot{0}$. 근 >

O

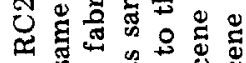
苛 ๓

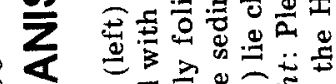

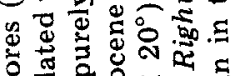
ปั

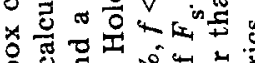
되듀 동 을

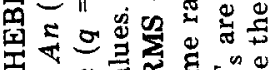
证 Iक ने o. इ以 三

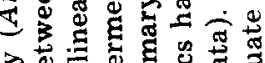
诺 웡 员要

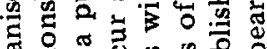

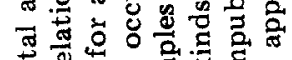
웡 कृ on $150^{n \circ}+\pi^{\circ}$ 4" รี क्चै है

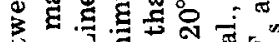

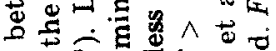
象

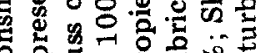

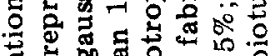
和 工 $\therefore$ 단

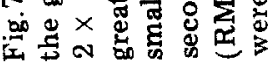


anisotropy magnitude in order to better understand the meaning of this parameter. The relationship between the total anisotropy, $A n$, and $F_{\mathrm{s}}$ is shown in Fig.7.

The total anisotropy, $A n$, can be defined as:

$A n=\frac{k_{\max }-k_{\min }}{k_{\text {ave }}} \times 100$

where:

$k_{\text {ave }}=\left(k_{\text {max }}+k_{\text {int }}+k_{\text {min }}\right) / 3$

$A n$ is the sum of lineation, $L$, and foliation, $F$, where:

$L=\frac{k_{\text {max }}-k_{\text {int }}}{k_{\text {ave }}} \times 100$

and:

$F=\frac{k_{\text {int }}-k_{\min }}{k_{\text {ave }}} \times 100$

We agree with Ellwood and Ledbetter (1977) that $F_{\mathrm{s}}$ is sensitive to $k_{\max }$, the value of the long-axis anisotropy, but it is also sensitive to the total anisotropy, $A n$ (Fig.7). For samples with $A n$ less than about $100 \%, F_{\mathrm{s}}$ for a lineated sediment will be larger than $F_{\mathrm{s}}$ for a foliated sediment with a similar $A n$. However, one cannot tell from $F_{\mathrm{s}}$ data alone whether larger values are due to increased particle alignment at a constant $A n$, or to a fabric with a similar shape (similar $q$ ), or even with a more foliated fabric, and a larger $A n$. Thus an $F_{\text {s }}$ of 1.05 will correspond to both a purely lineated fabric with a $5 \% A n$ and a purely foliated fabric with a $10 \%$ An (Fig.7). Since primary fabrics are dominantly foliated, increases in $F_{\mathrm{s}}$ are strongly tied to increases in $A n$. The relationships presented apply when the anisotropy and $F_{\mathrm{s}}$ are calculated using the same bulk susceptibility. If only $F_{\mathrm{s}}$ is normalized then the relationship between $F_{\mathrm{s}}$ and $A n$ cannot be mathematically defined, but since the standardized susceptibility is chosen to be close to the actual value (Ellwood and Ledbetter, 1977), the general relationship described here will still be observed although with more scatter.

The box-core samples have standardized $A n$ values less than $20 \%$, and $F_{\mathrm{s}}$ values which range from 1.01 to 1.16 (Fig.7) and fall within the predicted range. The highest $A n, F_{\text {s }}$ pair corresponds to a high- $q$ surface sediment of questionable origin, thus primary fabrics have $F_{\mathrm{s}}$ values ranging as high as 1.07. As previously discussed, most of the primary fabrics are foliar and most of the secondary fabrics are linear. This fabric distribution is reflected here since samples with $f>20^{\circ}$ have larger $F_{s}$ values than those with $f<20^{\circ}$ and similar $A n$. The $A n$ values of the Pleistocene sediments are much higher than those of the Holocene sediments, ranging as high as $125 \%$ with $F_{\text {s }}$ values as high as 2.3 (Fig.7). These Pleistocene sediments were not extensively bioturbated and primary sediment fabrics, mainly "contourite" laminations, are well preserved. Shor et al. (1984) suggest that these lamina- 
tions could have been deposited by both along-slope and down-slope flowing currents. The very high An values observed in the Pleistocene sediments may be due to the lack of bioturbation in these sediments.

\section{CONCLUSIONS}

We have demonstrated that, with appropriate and necessary precautions, the magnetic fabric of surficial sediment layers can be reliably measured. The use of a box corer appears to be essential for the undisturbed recovery of the upper few centimeters of the sediment surface. Careful steps must be taken to sample the surficial sediments in the box corer so as not to induce a secondary fabric. Gravity cores can probably be used to collect sediments in at least the upper half meter. However, in piston cores the magnetic fabric of the upper sediment layer is often disturbed during the coring process (Kent and Lowrie, 1975).

The AMS data can permit us to distinguish between primary and secondary magnetic fabrics. A primary fabric will have a low error (the anisotropy is well represented by a triaxial ellipsoid), a low $f$ value (the foliation is nearly parallel to the bedding plane), and a $q$ value smaller than 0.6 (the fabric is dominantly foliar rather than linear). These criteria for recognition of primary fabrics are based on extensive field observations and laboratory experiments (e.g., Rees et al., 1968) and are consistent with the nature of the sediments studied here. However, Auffret et al. (1981) permitted larger $f$ values to allow for the imbrication of magnetic grains, and Ellwood (1979) suggested that sediment grains which are oriented perpendicular to the flow can have unrestricted $f$ values due to the rolling of the grains. An imbricated fabric could be present in $\mathrm{BC} 3$, but no evidence was seen for the rolling of grains.

Workers who have been using $F_{\mathrm{s}}$ as a measure of sample anisotropy may have been discussing the total anisotropy of the sample rather than the linear fabric alone as $F_{\mathrm{s}}$ is strongly related to the total anisotropy $(A n)$. Both primary and secondary fabrics can have high values of $F_{\mathrm{s}}$. On the Nova Scotian continental rise samples of non-bioturbated Pleistocene sediment have higher $A n$ than bioturbated Holocene sediments suggesting at least in part that bioturbation reduces the strength of the anisotropy, although there may also be significant changes in sediment grain size and composition between Holocene and Pleistocene times. Since strong bottom currents are likely to deposit laminated sediments, higher $A n$ (and $F_{s}$ ) may in fact be found where there is significant bottom current activity (and little bioturbation). However, $F_{\mathrm{s}}$ alone does not appear to be an adequate parameter for describing a current-deposited sediment fabric.

In this study we note that the upper $1.5 \mathrm{~cm}$ of laminated sediment contains a primary magnetic fabric while the burrowed sediments deeper than $2.5 \mathrm{~cm}$ have a secondary fabric, although six of the samples from the deeper layer may have retained a primary fabric. The primary fabric is apparently due to the gravitational settling of particles from a fluid under the influence 
of bottom currents, while the secondary fabric results from mixing of the sediments by burrowing organisms.

The orientation of the $k_{\max }$ direction is the most difficult parameter to measure and interpret for these weakly anisotropic samples. The $k_{\max }$ directions for the primary sediment fabrics are generally alongslope, parallel to the mean bottom currents in the area. However, there is also a grouping of $k_{\max }$ axes perpendicular to the mean current direction. Since there is at present little evidence for downslope processes affecting the uppermost sediments in the area, it is entirely possible that the different $k_{\max }$ orientations have been produced by the alongslope currents. The variability observed may represent a statistical distribution of anisotropy vectors within a single sedimentary layer caused by local variations in bottomcurrent flow directions, modes of sediment transport, or the presence of bed forms. Thus one cannot reliably determine a $k_{\max }$ orientation for these HEBBLE sediments from a single measurement, and similar problems may also occur in other regions. However, we should note that in some areas of the deep sea where bottom currents are active, such as the Blake-Bahama Outer Ridge farther to the south, long-term current meter records show that the deep currents are much steadier in direction and speed than they are in the HEBBLE area (compare the current meter records shown in Jenkins and Rhines, 1980, from the Blake-Bahama Outer Ridge, with those in Weatherly and Kelley, 1982, from the HEBBLE area). In those regions there may be less variability in $k_{\max }$ orientations.

This study demonstrates the need for a careful examination of magnetic fabric measurements in order to determine the reliability of those measurements and the nature of the sedimentary fabric studied. In this area of Holocene sediments only about $16 \%$ of the total samples, and only $6 \%$ of the sediments in the bioturbated layer, had a fabric which could be considered primary. Fewer samples would have been accepted if stricter rejection criteria were used. Under the assumption that the preferred alignment of magnetic grains is representative of that of the other grains, a similar degree of statistical and interpretative uncertainty encountered in the AMS data would be expected to be found in fabric measurements obtained by other methods, for example, optical measurements. The AMS technique is simply a rapid way to obtain a quantitative measure of sediment fabric in three dimensions. Detailed studies of sedimentary fabric will need to be undertaken in other well-known and instrumented areas before we will know in detail the factors which determine the details of the primary sediment fabric in deep-sea sediments.

\section{ACKNOWLEDGEMENTS}

This work was supported by National Science Foundation Grant OCE 8012897 and Office of Naval Research Contract N00014-80-C-0098, Scope EE. We thank C.D. Hollister for inviting us to collect samples on $R / V$ "Knorr" Cruise 101. Manuscript reviewed by Thomas Janecek and Ken Miller. Brooks 
Ellwood also provided valuable comments on an earlier draft. Contribution No. 3842 of the Lamont-Doherty Geological Observatory.

\section{REFERENCES}

Auffret, G.-A., Sichler, B. and Coleno, B., 1981. Deep-sea texture and magnetic fabric indicators of bottom currents regime. Oceanol. Acta, 4: 475-488.

Biscaye, P.E., Gardner, W.D., Zaneveld, R.J., Pak, H.S. and Tucholke, B.E., 1980. Nephels! Have we got nephels. EOS, Trans. Am. Geophys. Union, 61: p.1014.

Bullfinch, D.L., Ledbetter, M.L., Ellwood, B.B. and Balsam, W.L., 1982. The highvelocity core of the Western Boundary Undercurrent at the base of the U.S. continental rise. Science, 215: 970-973.

Crimes, T.P. and Oldershaw, M.A., 1967. Paleocurrent determinations by magnetic fabric measurements on the Cambrian rocks of St. Tudwal's Peninsula, North Wales. Geol. J., $5: 217-232$.

Ellwood, B.B., 1979. Particle flocculation: one possible control on the magnetization of deep-sea sediments. Geophys. Res. Lett., 6: 237-240.

Ellwood, B.B., 1980a. Application of the anisotropy of magnetic susceptibility method as an indicator of bottom-water flow direction. Mar. Geol., 34: M83-M90.

Ellwood, B.B., 1980b. Induced and remanent magnetic properties of marine sediments as indicators of depositional processes. Mar. Geol., 38: 233-244.

Ellwood, B.B. and Ledbetter, M.T., 1977. Antarctic bottom water fluctuations in the Vema Channel: effects of velocity changes on particle alignment and size. Earth Planet. Sci. Lett., 35: 189-198.

Ellwood, B.B. and Ledbetter, M.T., 1979. Paleocurrent indicators in deep-sea sediment. Science, 203: 1335-1337.

Ellwood, B.B., Ledbetter, M.T. and Johnson, D.A., 1979. Sedimentary fabric: a tool to delineate a high-velocity zone within a deep western Indian Ocean bottom current. Mar. Geol., 33: M51-M55.

Ericson, D.B., Ewing, M., Wollin, G. and Heezen, B.C., 1961. Atlantic Deep-Sea Sediment Cores. Geol. Soc. Am. Bull., 72: 193-286.

Granar, L., 1958. Magnetic measurements of Swedish varved sediments. Arkiv. Geofys., $3: 1-40$.

Hamilton, N. and Rees, A.I., 1970. The use of magnetic fabric in paleocurrent estimations. In: S.K. Runcorn (Editor), Paleogeophysics. Academic Press, New York, N Y., pp. $445-464$.

Hessler, R.R. and Jumars, P.A., 1974. Abyssal community analysis from replicate box cores in the central North Pacific. Deep-Sea Res., 21: 195-209.

Jenkins, W.J. and Rhines, P.B., 1980. Tritium in the deep North Atlantic Ocean. Nature, 286: $877-880$.

Kelley, E.A., Weatherly, G.L. and Evans, J.C., 1982. Correlation between surface Gulf Stream and bottom flow near 5000 meters depth. J. Phys. Oceanogr., 12: 1150-1153.

Kent, D.V. and Lowrie, W., 1975. On the magnetic susceptibility of deep-sea sediment. Geol. Soc. Am. Bull., 87: 321-339.

King, R.F. and Rees, A.I., 1962. The measurement of the anisotropy of magnetic susceptibility of rocks by the torque method. J. Geophys. Res., 67: 1565-1572.

Ledbetter, M.T. and Ellwood, B.B., 1980. Spatial and temporal changes in bottom water velocity and direction from analysis of partical size data and alignment in deep-sea sediment. Mar. Geol., 38: 245--261.

Nowell, A.R.M., Hollister, C.D. and Jumars, P.A., 1972. High Energy Benthic Boundary Layer Experiment: HEBBLE. EOS, Trans. Am. Geophys. Union, 63: 594-595.

Opdyke, N.D., 1972. Paleomagnetism of deep-sea cores. Rev. Geophys. Space Phys., 10 : $213-249$.

Pak, H., 1983. Fluctuations of beam-attenuation coefficient in the lowest $2 \mathrm{~m}$ on the continental rise off Nova Scotia. Mar. Geol., 51: 77-97. 
Rees, A.I., 1965. The use of anisotropy of magnetic susceptibility in the estimation of sedimentary fabric. Sedimentology, 4: 257-271.

Rees, A.I. and Frederick, D., 1974. The magnetic fabric of samples from the Deep Sea Drilling Project, Legs I-IV. J. Sediment. Petrol., 44: 655-662.

Rees, A.I., Von Rad, U. and Shephard, F.P., 1968. Magnetic fabric of sediments from the La Jolla Submarine Canyon and fan, California. Mar. Geol., 6: 145-179.

Rees, A.I., Brown, C.M., Hailwood, E.A. and Riddy, P.J., 1982. Magnetic fabric of bioturbated sediments from the northern Rockall Trough: comparison with modern currents. Mar. Geol., 46: 161-173.

Richardson, M.J., Wimbush, M. and Mayer, L., 1981. Exceptionally strong near-bottom flows on the continental rise off Nova Scotia. Science, 213: 887-888.

Shor, A.N., Kent, D.V. and Flood, R.D., 1984. Contourite or turbidite? Magnetic fabric of fine-grained Quaternary sediments, Nova Scotia continental rise. In: D.A.V. Stow and D.J.W. Piper (Editors), Fine-Grained Sediments. Geol. Soc. London, Spec. Publ. 15: 257-273.

Spinrad, R.W. and Zaneveld, J.R.V., 1982. An analysis of the optical features of the near-bottom nepheloid layers in the area of the Scotian rise. J. Geophys. Res., 87: 9553-9561.

Tucholke, B.E., 1982. Origin of longitudinal triangular ripples on the Nova Scotian continental rise. Nature, 296: 735-737.

Weatherly, G.L. and Kelley Jr., E.A., 1982. "Too cold" bottom layers at the base of the Scotian Rise. J. Mar. Res., 40: 985-1012.

Yingst, J.Y. and Aller, R.C., 1982. Biological activity and associated sedimentary structures in HEBBLE-area deposits, western North Atlantic. Mar. Geol., 48: M7-M15. 